\title{
AVALIAÇÃO ECONÔMICA DA UTILIZAÇÃO DO TRATAMENTO SELETIVO NAS INFECÇÕES PARASITÁRIAS EM OVINOS
}

\author{
(Economic evaluation of the use of selective treatment in parasitic infections in sheep) \\ ${ }^{1}$ Maria Christine Rizzon Cintra, ${ }^{1}$ Douglas Luís Vieira, ${ }^{2}$ Eliton Aparecido Rezende, ${ }^{1}$ Marcelo Beltrão Molento \\ 1Universidade Federal do Paraná, Curitiba, Paraná, Brasil. ²Centro Universitário UniCesumar, Paraná, Brasil. \\ *Correspondência: douglasluisvieira@gmail.com
}

RESUMO: A ovinocultura é uma considerável fonte de renda para pequenos produtores, como também importante para a produção e exportação de produtos como carne, leite e seus derivados, e lã. Considerando que as helmintoses gastrintestinais em pequenos ruminantes estão listadas como uma das principais causas de diminuição na produção, elas também são responsáveis pelo alto gasto com produtos anti-helmínticos. O objetivo do presente trabalho foi comparar o custo-benefício da implementação do tratamento seletivo para o controle das endoparasitoses em comparação com o tratamento sistemático em todo o rebanho. A propriedade estudada está situada no município de Colombo, região metropolitana de Curitiba. A propriedade apresenta 30 matrizes mestiças das raças Texel e île-de-France e um reprodutor, trocado a cada ano, também das respectivas raças. As ovelhas são criadas em sistema semi-intensivo, com pastagem nativa e suplementadas com silagem e concentrado. Previamente ao início da rotina de acompanhamento da propriedade, foi realizado o teste de redução na contagem de ovos nas fezes para a determinação do anti-helmíntico eficaz na população parasitária e consequentemente o utilizado no tratamento seletivo. O medicamento Levamisol apresentou a melhor eficácia (88\%). Foram realizadas análises mensais durantes os meses de fevereiro até dezembro do ano de 2019, anotando o custo das doses de anti-helmíntico com a utilização do tratamento seletivo (análise real dos dados) e em relação ao custo do tratamento sistemático (análise hipotética). Para a análise hipotética dos custos do tratamento, foram selecionados seis princípios ativos mais utilizados na região, sendo: ivermectina, monopantel, moxidectina, nitroxinil e levamisol. Estabeleceu-se uma média de peso de $60 \mathrm{~kg}$ para a determinação da dosagem. $O$ cálculo do tratamento sistemático por princípio ativo foi realizado através da seguinte fórmula: $n^{\circ}$ de animais avaliados no mês $x$ dosagem de cada princípio ativo $\mathrm{x}$ o valor do princípio ativo. Os animais que receberam tratamento seletivo foram os que apresentaram FAMACHA 3, 4 ou 5, escore corporal menor que 2 e sinal clínico de edema submandibular. Em comparação com o tratamento seletivo $(R \$ 7,25)$, todos os grupos de tratamento sistemático apresentaram maior custo com anti-helmínticos. Os grupos apresentaram as seguintes médias de custo, albendazol com $R \$ 7,71$, levamisol $R \$ 11,34$, ivermectina $R \$ 15,42$, moxidectina $R \$ 18,15$, nitroxinil $R \$ 25,86$ e monopantel que demonstrou maior diferença com custo médio de $R \$ 206,80$. Notamos essa maior diferença no último composto principalmente por ser o com maior valor do mercado. É perceptível que mesmo em produtos com preços parecidos e no caso do levamisol o mesmo, o tratamento seletivo demonstrou ser o mais econômico. Baseado nos resultados descritos e associado com bem-estar do rebanho e controle de resistência parasitária já relatados no sistema de tratamento seletivo, esse é o modo de controle parasitário mais indicado, afim de obter vantagens econômicas e bem-estar animal.

Palavras-chave: controle parasitário; resistência parasitária; bem-estar animal

Nota: Aprovado Comitê de Ética de Uso Animal, número 007.1/2018. UniCesumar 